\title{
Simultaneous determination of 148 pharmaceuticals and illicit drugs in sewage sludge based on ultrasound-assisted extraction and liquid chromatography-tandem mass spectrometry
}

\author{
Pablo Gago-Ferrero • Viola Borova • \\ Marilena E. Dasenaki • Nikolaos S. Thomaidis
}

Received: 26 November 2014 / Revised: 3 February 2015 / Accepted: 6 February 2015 / Published online: 26 February 2015

(C) Springer-Verlag Berlin Heidelberg 2015

\begin{abstract}
This paper describes the development and validation of a new method for the simultaneous determination of 148 substances in sewage sludge. The selected compounds belong to different classes of pharmaceuticals, including antibiotics, analgesic and/or anti-inflammatory drugs, antiepileptics, benzodiazepines, antipsychotics, and antidepressants, among others, and illicit drugs, including opiates, opioids, cocaine, amphetamines, cannabinoids, and their metabolites. As far as the authors are aware, this is the first method in the peer-reviewed literature covering such a large number of target drugs for determination in a complex matrix like sewage sludge. The method presented herein combines ultrasoundassisted extraction (USE) and liquid chromatography coupled to tandem mass spectrometry. Good analytical performance was achieved, with limit-of-detection values below $10 \mathrm{ng} \mathrm{g}^{-1} \mathrm{~d}$.w. for $91 \%$ of the analytes and absolute recovery in the range $50-110 \%$ for more than $77 \%$ of the studied compounds. A combination of methanol and acidified water, also containing EDTA, proved to be the optimum solvent mixture to perform the extractions. An extra solid-phaseextraction clean-up step was not required, substantially reducing sample-preparation time and solvent consumption. Finally, the developed method was applied to the analysis of dif-
\end{abstract}

Published in the topical collection Advances in LC-MS/MS Analysis with guest editors Damià Barceló and Mira Petrovic.

Pablo Gago-Ferrero and Viola Borova contributed equally to this work.

Electronic supplementary material The online version of this article (doi:10.1007/s00216-015-8540-6) contains supplementary material, which is available to authorized users.

P. Gago-Ferrero • V. Borova • M. E. Dasenaki • N. S. Thomaidis $(\bowtie)$ Laboratory of Analytical Chemistry, Department of Chemistry,

University of Athens, Panepistimiopolis Zografou,

15771 Athens, Greece

e-mail: ntho@chem.uoa.gr ferent sewage-sludge samples from five wastewater treatment plants of Santorini Island (Greece). Out of the 148 target compounds, 36 were detected. Several compounds, including acetylsalicylic acid, citalopram, and ciprofloxacin among others, had maximum concentrations above $100 \mathrm{ng} \mathrm{g}^{-1}$ d.w.

Keywords Sewage sludge $\cdot$ Pharmaceuticals $\cdot$ Illicit drugs · LC-MS/MS · USE

\section{Introduction}

Pharmaceuticals and illicit drugs comprise a large and diverse group of compounds designed either to be highly active and interact with receptors in humans or to be toxic for many pathogen organisms. After intake, these active compounds undergo metabolic processes in organisms. Both parent compounds and metabolites are excreted into raw sewage and enter wastewater treatment systems. Because conventional wastewater treatment processes have been revealed not to remove these substances completely [1-3], excretion followed by wastewater treatment is believed to be the primary pathway of pharmaceuticals and illicit drugs into the environment. Despite low concentrations, effects of these substances on the environment and human health cannot be excluded. Several toxic effects on aquatic organisms have been described for many of these substances $[1,4-6]$, and their presence in the ecosystem is of concern. Although the main entry of pharmaceuticals and illicit drugs into the environment is through wastewater-treatment-plant (WWTP) effluents, it should be pointed out that a smaller but important fraction of these substances remain in the sewage sludge and may be released into 
the environment through sewage application. The mechanisms that control sorption onto sludge are complex and do not only depend on the lipophilicity of the compounds. Other factors, including solubility, vapor pressure, and the environmental conditions (temperature, air disturbance, or soil organic-matter content), are also important [7]. Therefore, sorption processes are difficult to predict. Efforts to improve water quality have led to a substantial increase in sewage loads. Currently, the amount of sewage sludge generated per person per day on average in Europe is estimated to be $90 \mathrm{~g}$ d.w. [8]. Biosolids produced are mainly reused in agriculture as soil improvement or disposed of to landfill. Despite the clear benefits of these practices, which result in the recycling of nutrients and organic matter, these routes constitute an additional route of entry of organic pollutants to the environment. Consequently, detailed study of the presence of pharmaceuticals and illicit drugs in sewage sludge is necessary to acquire a complete description of the distribution of these emerging pollutants in the environment and to perform a reliable risk assessment.

Several analytical methods for the determination of pharmaceuticals and illicit drugs have been developed and their presence has been widely assessed in surface water, sediments, and wastewater $[4,9,10]$, revealing relevant levels of these compounds. A small proportion of the studies dealing with wastewater also considered the proportion attached to suspended particulate material, where these substances were also determined [11]. However, analytical methods for and data on the occurrence of pharmaceuticals and illicit drugs in sewage sludge are not abundant. Because these compounds have a wide range of psychochemical properties and include many polar and non-volatile substances, the most suitable technique for their detection is liquid chromatography coupled to tandem mass spectrometry (LC-MS/MS) because of its versatility, specificity, and selectivity [12, 13]. A few methods have been developed for the determination of pharmaceuticals in sewage sludge $[9,14-16]$, in some cases including an extensive list of up to 43 compounds [15]. The determined concentrations vary, but they are normally below $100 \mathrm{ng} \mathrm{g}^{-1}$ d.w. $[9,16]$. For illicit drugs only two methods have been proposed, covering a wide variety of these compounds (20 and 13, respectively, in Refs. [17, 18]). Before this work, only a few of these substances (amphetamine, methamphetamine, MDMA, and cocaine) had been investigated in sewage sludge, in most cases as part of a multiresidue study that mainly included pharmaceuticals [19-21]. The concentration ranges for these compounds are similar to those determined for pharmaceuticals, with higher values for cannabinoids (particularly for the parent compounds) because of their higher lipophilicity $[17,18]$. To date, an analytical method for the simultaneous analysis of an extensive list of pharmaceuticals and illicit drugs in sewage sludge has not been developed.
The objective of this study was to develop and validate a robust and sensitive multi-analyte method for the simultaneous determination of 148 different substances, including relevant related metabolites, in sewage sludge. The target compounds belong to different therapeutic groups of pharmaceuticals (antibiotics, NSAIDs, antilipidemics, antiepileptics, analgesics, antihypertensives, diuretics, steroids, antiulcers, anesthetics, benzodiazepines, antipsychotics, barbiturates, and antidepressants (tricyclic, tetracyclic, selective serotonin re-uptake inhibitors (SSRIs), and serotonin-norepinephrine re-uptake inhibitors (SNRIs)) and of sympathomimetics and illicit drugs (opiates, opioids and related metabolites (including some non-illicit compounds), cocaine and related metabolites, amphetamines, and hallucinogens (cannabinoids, lysergic acid diethylamide (LSD), and derivatives)). Target analytes were extracted by ultrasound-assisted extraction (USE) using a mixture of water and methanol (MeOH). No further clean-up step was necessary, substantially reducing the overall analysis time. The extracts were further analyzed by LC-MS/MS. The suitability of the developed method was tested by the trace determination of the selected target pharmaceuticals and illicit drugs in sewage sludge obtained from five WWTPs of Santorini (Greece), providing new knowledge regarding the presence of these substances in this matrix.

\section{Experimental}

\section{Standards and reagents}

CAS numbers, molecular formulas, molecular weight $\mathrm{mol}^{-1}$ ), and other relevant properties of all target compounds are summarized in ESM Table S1. All pharmaceutical standards were of high purity grade ( $>90 \%)$ and were purchased from Sigma-Aldrich (Athens, Greece) and LGC Promochem (Molsheim, France) with the exception of sulfadoxine and sulfaclozine, which were donated by the National Laboratory of Residue Analysis of Food of Animal Origin of the Hellenic Ministry of Rural Development and Food. Regarding psychotropic and illicit drugs, all target analytes were of high purity ( $98 \%$ ). Solutions or solids were purchased from LGC Promochem (Molsheim, France) with the exception of topiramate and lamotrigine, which were obtained from Glenmark (Mahwah, NJ, USA) and Sigma-Aldrich Chemie $\mathrm{GmbH}$ (Steinheim, Germany), respectively. The illicit deuterated compounds morphine-D3 (MOR-D3), codeine-D3 (COD-D3), cocaine-D3 (COC-D3), 2-ethylidene-1,5-dimethyl-3,3-diphenylpyrrolidine-D3 (EDDP-D3), ecgonine methyl ester-D3 (EME-D3), 3,4-methylenedioxy-Nmethylamphetamine-D 5 (MDMA-D 5), 3,4methylenedioxyamphetamine-D5) (MDA-D5), tetrahydrocannabinol-D3 (THC-D3), tetrahydrocannabinolic acid-D3 (THCA-D3), and lysergic acid diethylamide-D3 
(LSD-D3) were also obtained from LGC Promochem (Molsheim, France). Acetonitrile (ACN), hydrochloric acid ( $37 \%$ ), and $\mathrm{MeOH}$ LC-MS grade were purchased from Merck (Darmstadt, Germany), and formic acid (FA) $99 \%$ was obtained from Sigma-Aldrich, Fluka (Buchs, Switzerland). Acetone (99.8\% purity) was purchased from Carlo Erba Reagents (Val-de-Reuil, France). Ethyl acetate (EtAc) (analytical reagent grade, $99.9 \%$ ) was obtained from Fisher Chemicals (Loughborough, UK). Distilled water was provided by a Milli-Q purification apparatus (Millipore Direct-Q UV, Bedford, MA, USA). Syringe filters (RC) of $4 \mathrm{~mm}$ diameter and pore size $0.2 \mu \mathrm{m}$ were obtained from Phenomenex (Torrance, CA, USA). Approximately $10 \mathrm{mg}$ each standard was accurately weighed and placed in a $10 \mathrm{~mL}$ volumetric flask. Penicillins, cephalosporines, macrolides, and metformin were dissolved in Milli-Q-water, and all other analytes were dissolved in $\mathrm{MeOH}$. Stock solutions of $1.0 \mathrm{mg} \mathrm{L}^{-1}$ of each compound were obtained and stored at $-20{ }^{\circ} \mathrm{C}$. From this multi-analyte solution all working solutions were prepared daily by appropriate dilution of the stock standard mixture (1.0 $\left.\mathrm{mg} \mathrm{L}^{-1}\right)$ and IS solutions $\left(1.0 \mathrm{mg} \mathrm{L}^{-1}\right.$, containing all the aforementioned deuterated standards) in $\mathrm{MeOH}$. Calibration standards were prepared by serial dilution of the mixed working solution using Milli-Q water with $0.05 \%(v / v)$ formic acid, resulting in individual concentrations ranging from 0.2 to $100 \mu \mathrm{g} \mathrm{L}^{-1}$.

\section{Sample collection and preparation}

Treated sewage-sludge samples were collected in July 2013 from five WWTPs of Santorini, an island located in the southern Aegean Sea (Greece). Sampling locations are described in detail in a study by Borova et al. [22]. The plants of Kamari, Fira, and Ia are located in very touristy spots, where in summer periods (when this monitoring was performed) the population increases substantially. Karterados and Emporio WWTPs serve a more stable population which does not experience the effects of tourism in such a pronounced way.

The studied WWTPs serve population equivalents in the range 3,000 to 16,000 people. The wastewater treatment in all the investigated WWTPs consists of a preliminary clarification step followed by a biological treatment consisting of the conventional activated sludge process (CAS). The generated sludge is treated in two stages: aeration and dewatering. Anaerobic digestion is not performed. The average sludge production in the studied WWTPs ranged from 390 to $3500 \mathrm{~kg}$ day $^{-1}$.

Different grab samples were randomly collected and combined at each WWTP, providing a final sample weighing approximately $500 \mathrm{~g}$. Samples were collected in antimicrobial plastic bags after sewage-sludge dewatering, properly sealed, and shipped in refrigerated coolers to the laboratory. They were then freeze-dried and stored in the dark at $-20{ }^{\circ} \mathrm{C}$ until analysis.

\section{Extraction}

In the optimized method, $0.1 \mathrm{~g}$ freeze-dried sewage sludge was placed in a plastic centrifuge tube $(15 \mathrm{~mL})$, spiked with the corresponding surrogates, and kept in contact overnight. The sample was then extracted with $2 \mathrm{~mL} \mathrm{MeOH}-$ Milli-Q water (pH 2.5, FA $0.5 \%$ and $0.1 \%$ EDTA), 50:50 $(v / v)$, by vortex $(1 \mathrm{~min})$, followed by ultrasonic extraction for $15 \mathrm{~min}$ at $50{ }^{\circ} \mathrm{C}$. After the extraction the extract was centrifuged for $10 \mathrm{~min}$ (4000 rpm) and the supernatant was collected in a glass test tube. This procedure was repeated two more times. In total $6 \mathrm{~mL}$ supernatant was collected. Then the total extract was evaporated to dryness under a gentle steam of $\mathrm{N}_{2}$ at $40^{\circ} \mathrm{C}$. Reconstitution of the analytes was performed with $0.5 \mathrm{~mL}$ $\mathrm{MeOH}-$ water $(0.05 \% \mathrm{FA}), 25: 75(v / v)$. Finally, the extract was filtered through a $0.2 \mu \mathrm{m} \mathrm{RC}$ syringe filter and then the samples were transferred to a glass vial for HPLC-MS/MS analysis.

\section{LC-MS/MS analysis}

The LC-MS/MS method for the analysis of the 148 target analytes was developed by merging two existing methods for pharmaceuticals and drugs of abuse [22, 23]. Instrumental analysis was performed with a Thermo UHPLC Accela system connected to a TSQ Quantum Access triple-quadrupole mass spectrometer from Thermo Electron Corporation (San Jose, CA, USA) equipped with an electrospray-ionization (ESI) source (Thermo IonMAX) operated in both positive and negative mode. Chromatographic separation was achieved on an Atlantis T3 C18 $(100 \times 2.1 \mathrm{~mm}, 3 \mu \mathrm{m})$ column from Waters Corporation (Milford, MS, USA). The mobile phase for the positive-detection mode consisted of water $(0.01 \% \mathrm{FA}(v / v))$ and $\mathrm{MeOH}$, and that for the negativedetection mode consisted of water $\left(1 \mathrm{mmol} \mathrm{L}{ }^{-1}\right.$ ammonium formate), $\mathrm{MeOH}$, and $\mathrm{ACN}$ (at a constant proportion of $5 \%$ ).

The elution gradient for $\mathrm{ESI}(+)$ mode started with $5 \%$ $\mathrm{MeOH}$ for $3 \mathrm{~min}$, then increasing to $100 \%$ in $17 \mathrm{~min}$, held at $100 \%$ for $9 \mathrm{~min}$, and finally returning to the initial conditions in the next minute. The necessary time for the reequilibration of the analytical column was $15 \mathrm{~min}$. The total run time for each injection was $45 \mathrm{~min}$. The $\mathrm{ESI}(+)$ operational settings were: capillary voltage, $3500 \mathrm{~V}$; capillary temperature, $270{ }^{\circ} \mathrm{C}$; sheath gas, $30 \mathrm{psi}$; and auxiliary (drying) gas, 10 a.u. The elution gradient for ESI(-) started with $25 \%$ $\mathrm{MeOH}$ and $5 \% \mathrm{ACN}$ (which was kept constant throughout the elution). $\mathrm{MeOH}$ was then increased to $95 \%$ in $10 \mathrm{~min}$ and kept constant for $13 \mathrm{~min}$, before a return to the initial conditions over the next minute. The time for the re-equilibration was $13 \mathrm{~min}$. The total run time for each injection was $37 \mathrm{~min}$. 
The ESI(-) operational settings were: capillary voltage, $2500 \mathrm{~V}$; capillary temperature, $270{ }^{\circ} \mathrm{C}$; sheath gas, $20 \mathrm{psi}$; and auxiliary (drying) gas 10 a.u. In both cases the injection volume was set to $10 \mu \mathrm{L}$ and the mobile-phase flow to $100 \mu \mathrm{L} \mathrm{min}{ }^{-1}$.

The optimized ionization mode, fragmentation voltages, and collision energies for each compound have been described in detail by Borova et al. and Dasenaki et al. [22, 23]. Data acquisition and evaluation were performed with Excalibur software (Thermo Electron Corporation). Identification and quantification were performed in selected-reactionmonitoring (SRM) mode, recording the transitions between the precursor ion and the two most abundant product ions for each target analyte, thus achieving four identification points per compound (2002/657/EC).

\section{Validation}

The developed method was evaluated under the optimized conditions in terms of linearity range, sensitivity, accuracy, reproducibility, and matrix effects.

A Certified Reference Material (CRM 145R, sewage sludge) from the European Commission was used for method development and validation. Spiked samples at a concentration of $40 \mathrm{ng} \mathrm{g}^{-1}$ d.w. were extracted sixfold. The CRM was certified for metals and was never analyzed for emerging contaminants (Description of the CRM properties: http://www. irmm.jrc.be/html/reference_materials_catalogue/catalogue/ attachements/BCR-145r_cert.pdf). However, the presence of the target compounds was evaluated and positive results were obtained for 10 of the 148 analytes. None of the analyzed illicit drugs were detected in the CRM. The detected concentrations in the CRM145R sample are summarized in ESM Table S2.

Blank tests were performed to rule out possible contamination from the sampling, storage, or instrumentation. To comply with internal quality-control procedures, two control spiked samples, two solvent injections, and two procedural blanks were inserted into each analytical batch of twelve samples. The individual values obtained for control samples were plotted on a process-behavior chart throughout the study to establish whether the analysis was in a state of statistical control.

\section{Results and discussion}

\section{Chromatography optimization}

While merging the two methods on which the presented method is based [22,23], different variables were investigated and optimized to achieve the best compromise conditions for all compounds.
An Atlantis T3 C18 column $(100 \times 2.1 \mathrm{~mm}, 3 \mu \mathrm{m})$, previously used for the analysis of 89 pharmaceuticals [23], was selected for the analysis of the 148 compounds because it had an overall good performance for both pharmaceutical and illicit-drug compounds. Both sensitivity and peak shape worsened significantly for morphine and ecgonine methyl ester (EME) when using the Atlantis T3 C18 column compared with the pentafluorophenyl (PFP) column used in Ref. [22]. For some other illicit drugs the sensitivity decreased slightly, but these changes were not significant. However, the PFP column presented many more problems for several pharmaceuticals, particularly the most lipophilic ones.

$\mathrm{MeOH}$ had a better overall performance than ACN for most of the studied compounds (e.g. penicillins, betablockers, steroids, opioids and opiates, cocaine compounds, antidepressants, anesthetics, benzodiazepines, amphetamine compounds, and antiepileptics). FA was added in the aqueous phase because its addition at low concentrations resulted in a significant improvement in peak shape and sensitivity when working in $\operatorname{ESI}(+)$. The mobile phase of choice for the $\operatorname{ESI}(+)$ detection mode consisted of water $(0.01 \% \mathrm{FA}(v / v))$ and $\mathrm{MeOH}$ as organic phase. Although the increase of FA to $0.05 \%(v / v)$ positively affected the sensitivity for some drugs (e.g. antipsychotics), it usually had a negative effect for pharmaceuticals. Acidic additives in the organic phase were also tested, revealing that for most pharmaceuticals this caused a decrease in sensitivity. However, it was observed that the addition of a small amount of FA into the vial before injection into the LC-MS/MS system led to a very significant improvement of the sensitivity for many compounds. Figure S3a (Electronic Supplementary Material (ESM)) shows the effect of this condition for the different compound families studied. For some compounds, including some benzodiazepines, antibiotics, and NSAIDs, the sensitivity decreased on adding FA. For other substances, including many amphoteric compounds (e.g. sulfonamides), changes in acidic or basic conditions had little effect. However, most substances experienced a clear improvement. For some compounds (e.g. morphine and olanzapine) a significant increase in sensitivity was obtained on increasing FA concentration from 0.01 to $0.1 \%(v / v)$. However, the behavior of most of the compounds changed little in that FA concentration range. A final FA concentration of $0.05 \%(v / v)$ was chosen to achieve the best compromise conditions.

In ESI(-) mode the conditions described by Dasenaki et al. [23] were used, because they resulted in an overall good performance of the analytical method for all the compounds.

Figure S3b shows the SRM chromatograms for all the target analytes under the optimized LC-MS/MS conditions. The SRM transitions used for quantification, the chromatography retention times, and the ESI mode used for each compound are also indicated in this figure. 


\section{USE extraction}

USE was the technique of choice because it provided short extraction times, low solvent consumption, and good recoveries. Another reason was the fact that it can process a large number of samples simultaneously, thereby reducing the total time of the sample preparation before the instrumental analysis.

In the optimization of a method using USE, extraction solvent mixture and extraction temperature are the most important conditions. The optimization of these crucial factors was performed by analyzing treated sludge $(0.1 \mathrm{~g})$ spiked in triplicate to $100 \mathrm{ng} \mathrm{g}^{-1}$ d.w. and blank samples, and calculating recoveries on the basis of peak area for each tested condition. Because of the wide range of physicochemical properties of the compounds selected for this study, a solvent with some organic content in water (possibly a different combination for each separate analyte) was likely to provide the best recoveries. Different solvent mixtures were tested to optimize the procedure, including water, water- $\mathrm{MeOH}$ 1:1 $(v / v), \mathrm{MeOH}$, acetone, water-MeOH-acetone 1:1:1 ( $v / v)$, EtAc, water$\mathrm{MeOH}-\mathrm{EtAc}$ 1:1:1 ( $v / v)$, and ACN. As some studies suggest, acidic conditions can lead to higher extraction efficiencies for the compounds of interest [11, 24, 25]. Better recoveries for most compounds were obtained when using acidified water (FA $0.5 \%,(v / v))$ instead of water, as can be observed from Fig. 1a (combinations S1 and S3). Therefore, the rest of the experiments were performed using acidified water. EDTA was added to all the solvent mixtures during optimization because it was proved in previous experiments to improve the extraction recoveries. The temperature for these experiments was set to $40{ }^{\circ} \mathrm{C}$. The recoveries obtained when the different mixtures were tested are shown in Fig. 1a and ESM Table S4. The best results were obtained by using three $\times 2 \mathrm{~mL}$ of a mixture of acidified water with formic acid $0.5 \%(\mathrm{pH}=2.5)$ and $0.1 \%$ EDTA-MeOH $(1: 1,(v / v))$. Under these conditions more than $70 \%$ of the analytes were extracted, with an absolute recovery in the range $50-120 \%$. These conditions also resulted in the lowest number of compounds with recoveries below $20 \%$ ( $8 \%$ of the analytes). In almost every case, the use of acetone, EtAc, or ACN did not improve the results.

Temperature is another important variable. Low temperature can lead to lower extraction efficiency, but too-high temperatures can also decrease recoveries. This may be the result of thermal degradation of analytes or loss of selectivity in the method, leading to the more efficient release of interfering matrix components [11]. The objective was to find the temperature which enables the maximum recovery without giving rise to a significant increase of matrix effect. Figure $1 \mathrm{~b}$ shows the results obtained at $40{ }^{\circ} \mathrm{C}, 50^{\circ} \mathrm{C}$, and $60^{\circ} \mathrm{C}$. The increase in temperature to $50^{\circ} \mathrm{C}$ led to a slight increase in the recovery of some compounds, whereas the rest remained stable. On increasing the temperature to $60{ }^{\circ} \mathrm{C}$ there was a significant decrease in the extraction efficiency for some analytes, and an increase in recoveries above $120 \%$. These results are probably a consequence of the increased interfering matrix components that were co-extracted under these conditions. However, some analytes had higher extraction efficiencies at that temperature (e.g. cefalosporines, salicylic acid, and several benzodiazepines). Finally, $50^{\circ} \mathrm{C}$ was selected as the optimum temperature for the extractions, providing the best compromise conditions for all compounds.

The amount of sample used in the extraction was also studied. Experiments with 0.2, 0.5, and $1 \mathrm{~g}$ were conducted but did not lead to lower method limits of detection (MLODs) than the experiments performed with $0.1 \mathrm{~g}$, whereas recoveries decreased and matrix effect increased. As in the case of increased temperature, this may be caused by the co-extraction of interfering matrix components that negatively affect sensitivity.

\section{Method validation}

The identification and confirmation criteria for the analysis of the target substances were based on the Commission Decision $2002 / 657 / E C$. To confirm the presence of the compounds, the retention time of the compounds ( $2.5 \%$ of tolerance) and relationship between the two transitions (difference of less than $20 \%$ ) were compared. For each compound, the SRM transition with the highest intensity was used for quantification, and the other transition was used for confirmation. Quantification was based on standard additions, and isotopically labeled compounds were used only for the quantification of those compounds in which isotopic analogue compounds were available.

Seven-point calibration curves $\left(0.1-100 \mathrm{ng} \mathrm{mL}^{-1}\right.$, equivalent concentration in the sludge sample $0.5-500 \mathrm{ng} \mathrm{g}^{-1}$ d.w.) were generated using linear-regression analysis. The linearity was qualified by the linear correlation coefficient, $r^{2}$. The calibration curves obtained for the SRM transitions were linear, with $r^{2} \quad 0.99$ in all cases. Instrumental limits of detection and quantification for the target compounds and instrumental precision are described in Refs. [22, 23].

The main variables for the method performance are summarized in Table 1. MLODs and method limits of quantification (MLOQ) were calculated by analyzing the spiked samples seven times. For compounds at the relevant concentration in the blank (e.g. caffeine, doxycycline), replicate analyses of the same sample were performed. MLODs were calculated as follows: the standard deviation of the lowest spiked concentration ( $40 \mathrm{ng} \mathrm{g}^{-1}$ d.w.) or the standard deviation of the replicate analyses (for abundant compounds) was multiplied by three and then divided by the slope of the calibration curve of spiked samples. MLOD values were below $10 \mathrm{ng} \mathrm{g}^{-1}$ d.w. for more than $91 \%$ of the target compounds (Fig. 2a). MLODs were always below $20 \mathrm{ng} \mathrm{g}^{-1}$ d.w. The reported 

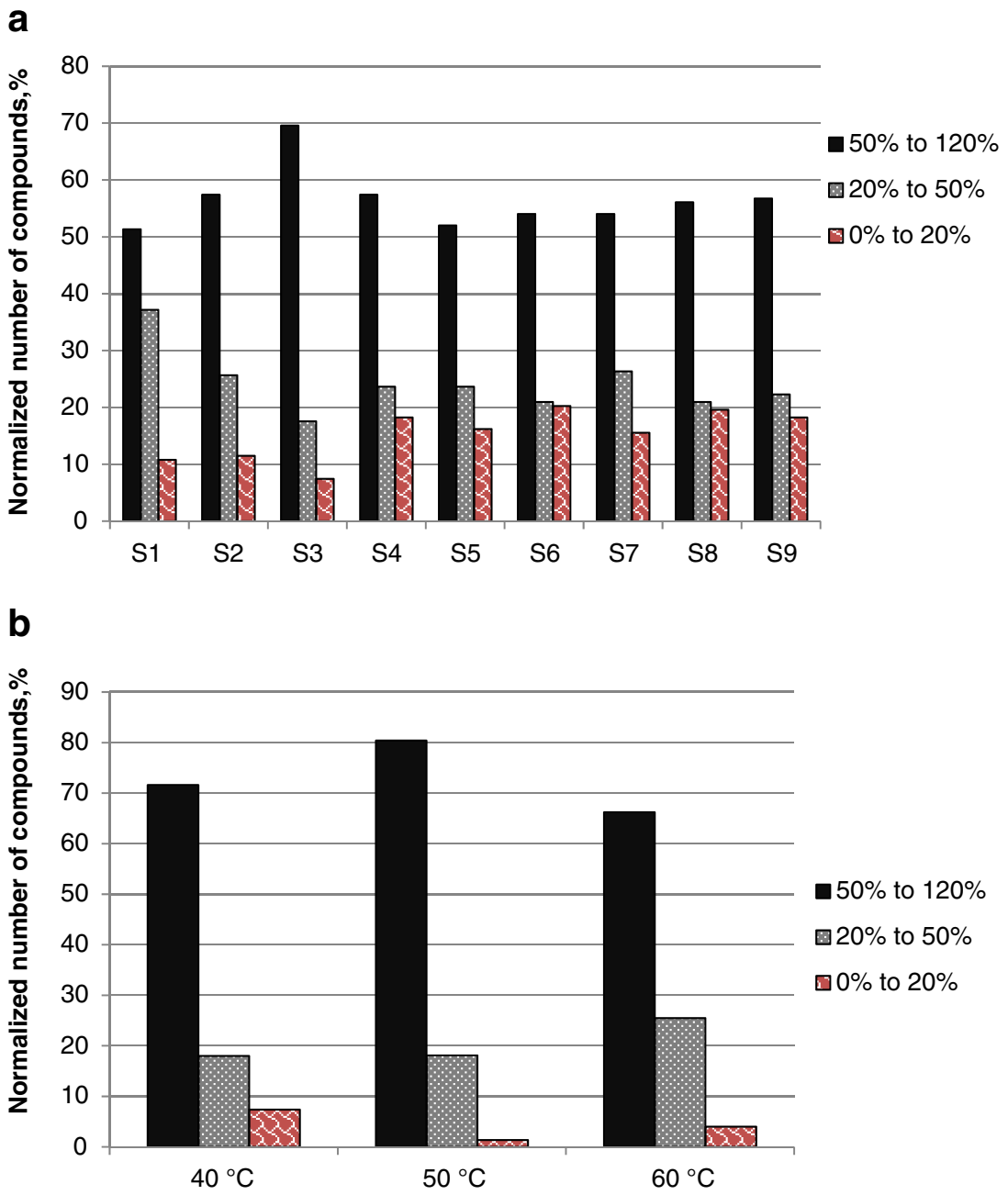

Fig. 1 Optimization of the (a) solvent mixture and (b) temperature. The color and pattern code refers to the different intervals of recovery efficiency. The temperature during ultrasound-assisted extraction was $40{ }^{\circ} \mathrm{C}$. S1: $3 \times 2 \mathrm{~mL}$ mixture of water with $0.1 \%$ EDTA-methanol (1:1). S2: $2 \mathrm{~mL}$ acidified water with formic acid $0.5 \%(\mathrm{pH}=2.5)$ and $0.1 \%$ EDTA, $2 \mathrm{~mL}$ mixture of acidified water with formic acid-methanol (1:1), $2 \mathrm{~mL}$ methanol. S3: $3 \times 2 \mathrm{~mL}$ mixture of acidified water with formic acid $0.5 \%(\mathrm{pH}=2.5)$ and $0.1 \%$ EDTA-methanol (1:1). Chosen conditions. S4: $2 \mathrm{~mL}$ acidified water with formic acid $0.5 \%(\mathrm{pH}=2.5)$ and $0.1 \%$ EDTA, $2 \mathrm{~mL}$ methanol, $2 \mathrm{~mL}$ acetone. $\mathrm{S} 5: 3 \times 2 \mathrm{~mL}$ mixture of acidified water with formic acid $0.5 \%(\mathrm{pH}=2.5)$ and $0.1 \%$ EDTAmethanol-acetone $(1: 1: 1)$. S6: $2 \mathrm{~mL}$ acidified water with formic acid $0.5 \%(\mathrm{pH}=2.5)$ and $0.1 \%$ EDTA, $2 \mathrm{~mL}$ methanol, $2 \mathrm{~mL}$ ethyl acetate. $\mathrm{S} 7: 3 \times 2 \mathrm{~mL}$ mixture of acidified water with formic acid $0.5 \%(\mathrm{pH}=2.5)$ and $0.1 \%$ EDTA-methanol-ethyl acetate (1:1:1). S8: $2 \mathrm{~mL}$ acidified water with formic acid $0.5 \%(\mathrm{pH}=2.5)$ and $0.1 \%$ EDTA, $2 \mathrm{~mL}$ methanol, $2 \mathrm{~mL}$ acetonitrile. S9: $3 \times 2 \mathrm{~mL}$ mixture of acidified water with formic acid $0.5 \%(\mathrm{pH}=2.5)$ and $0.1 \%$ EDTA-methanol-acetonitrile $(1: 1: 1)$
MLODs and MLOQs enable reliable detection and quantification of the target compounds at their typical levels in sewage-sludge samples. Recoveries of the overall method were calculated by analyzing sewage-sludge samples (CRM145R) $(n=6)$ fortified at $40 \mathrm{ng} \mathrm{g}^{-1}$ d.w. As indicated previously, the presence of the target analytes was investigated in the CRM material (results summarized in ESM Table S2). Although some compounds were detected, the concentrations in most cases were low and enabled an accurate estimation of the recoveries at the working concentration level. The compounds detected at high concentration (caffeine, ofloxacin, clozapine, doxycycline, and risperidone) were spiked at $100 \mathrm{ng} \mathrm{g}^{-1}$ d.w. Most of the studied compounds (77 \%) had recoveries in the range $50-110 \%$ (Fig. 2b), and more than $41 \%$ in the range $80-110 \%$. Only 10 out of the 148 studied compounds had recoveries below $30 \%$. These substances were among the most lipophilic ones, almost all of them with $\log K_{\mathrm{OW}}\left(K_{\mathrm{OW}}=\right.$ octanol-water distribution coefficient) values above four (chlorpromazine, clomipramine, and gemfibrozil, among others), revealing lower recovery efficiency for this type of compound. Considering that this study intended to analyze a large number of analytes with a wide range of psychochemical properties, the results were quite successful. Moreover, the low recoveries obtained in some cases were not regarded as an obstacle to their reliable determination, because their sensitivity and reproducibility were satisfactory. 
Table 1 Performance of the method

$\begin{array}{lllll}\begin{array}{lll}\text { MLOD } \\ \text { (ng g }^{-1}\end{array} & \begin{array}{l}\text { MLOQ } \\ \left(\text { ng g }^{-1}\right.\end{array} & \begin{array}{l}\text { REC (\%) }\left(40 \mathrm{ng} \mathrm{g}^{-1},\right. \\ \text { d.w. })\end{array} & \begin{array}{l}\text { RSD } \\ (\%)\end{array} & \begin{array}{l}\text { ME } \\ (\%)\end{array} \\ n=6) & (n=6) & \end{array}$

Pharmaceuticals

\begin{tabular}{|c|c|c|c|c|c|}
\hline 7-Aminoflunitrazepam & 7.5 & 24.8 & 35 & 10 & -60 \\
\hline 8-OH mirtazapine & 1.4 & 4.7 & 87 & 12 & -31 \\
\hline 9-OH Risperidone & 4.3 & 14.3 & 32 & 18 & -31 \\
\hline Acetylsalicylic acid & 13.8 & 46.0 & 126 & 20 & -84 \\
\hline Alprazolam & 3.2 & 10.6 & 73 & 16 & -18 \\
\hline Amitriptyline & 5.1 & 16.8 & 30 & 17 & -51 \\
\hline Amoxicillin & 16.4 & 54.7 & 62 & 20 & -64 \\
\hline Atenolol & 5.1 & 16.9 & 94 & 11 & -18 \\
\hline Atorvastatin & 2.7 & 9.1 & 31 & 16 & -23 \\
\hline Azithromycin & 6.5 & 21.6 & 92 & 19 & 63 \\
\hline Betamethasone & 4.4 & 14.7 & 77 & 14 & -56 \\
\hline Bromazepam & 1.0 & 3.5 & 68 & 13 & 11 \\
\hline Caffeine & 3.3 & 10.9 & 104 & 6 & -80 \\
\hline Carbamazepine & 4.4 & 14.7 & 76 & 12 & -19 \\
\hline Cefaclor & 0.8 & 2.7 & 90 & 19 & -64 \\
\hline Cefadroxil & 3.3 & 10.9 & 83 & 9 & -61 \\
\hline Cefalexin & 3.2 & 10.7 & 100 & 19 & -29 \\
\hline Cefazolin & 16.3 & 52.8 & 88 & 16 & -35 \\
\hline Chloramphenicol & 9.5 & 31.7 & 84 & 15 & -40 \\
\hline Chlordiazepoxide & 3.1 & 10.3 & 66 & 16 & -21 \\
\hline Chlorpromazine & 3.2 & 10.7 & 16 & 16 & -64 \\
\hline Chlortetracycline & 13.0 & 43.2 & 81 & 13 & -46 \\
\hline Cimetidine & 3.8 & 12.5 & 78 & 9 & -3 \\
\hline Ciprofloxacin & 3.2 & 10.7 & 107 & 9 & -76 \\
\hline Citalopram & 3.6 & 11.9 & 73 & 15 & -35 \\
\hline Clarithromycin & 3.3 & 11.0 & 73 & 8 & -25 \\
\hline Clobazam & 5.5 & 18.3 & 79 & 10 & -49 \\
\hline Clofibric acid & 8.3 & 27.9 & 87 & 11 & -15 \\
\hline Clomipramine & 5.0 & 16.5 & 21 & 12 & -58 \\
\hline Clozapine & 4.0 & 13.3 & 38 & 20 & -38 \\
\hline Cortisol & 5.5 & 18.4 & 94 & 12 & -52 \\
\hline Cortisone & 4.9 & 16.4 & 85 & 12 & -60 \\
\hline Diazepam & 5.5 & 18.4 & 52 & 20 & -16 \\
\hline Diclofenac & 10.3 & 34.1 & 27 & 14 & -18 \\
\hline Dicloxacillin & 19.9 & 66.3 & 79 & 17 & 90 \\
\hline Difloxacin & 4.1 & 13.5 & 43 & 13 & -13 \\
\hline Doxepin & 2.9 & 9.6 & 42 & 10 & 15 \\
\hline Doxycycline & 9.5 & 31.7 & 105 & 10 & -92 \\
\hline Enrofloxacin & 6.3 & 21.9 & 50 & 15 & 14 \\
\hline Ephedrine & 0.9 & 3.1 & 92 & 9 & -64 \\
\hline Fentanyl & 1.8 & 6.0 & 58 & 20 & -26 \\
\hline Florfenicol & 5.1 & 17.0 & 100 & 5 & -32 \\
\hline Flunitrazepam & 1.5 & 5.1 & 64 & 6 & -24 \\
\hline Fluoxetine & 5.3 & 17.5 & 19 & 7 & -59 \\
\hline Furosemide & 6.3 & 21.9 & 90 & 11 & -11 \\
\hline Gemfibrozil & 5.1 & 17.0 & 17 & 12 & -56 \\
\hline
\end{tabular}

Table 1 (continued)

\begin{tabular}{|c|c|c|c|c|c|}
\hline & $\begin{array}{l}\text { MLOD } \\
\text { (ng g } \\
\text { d.w.) }\end{array}$ & $\begin{array}{l}\text { MLOQ } \\
\text { (ng g } \\
\text { d.w.) }\end{array}$ & $\begin{array}{l}\operatorname{REC~}(\%) \\
\left(40 \mathrm{ng} \mathrm{g}^{-1},\right. \\
n=6)\end{array}$ & $\begin{array}{l}\text { RSD } \\
(\%) \\
(n=6)\end{array}$ & $\begin{array}{l}\mathrm{ME} \\
(\%)\end{array}$ \\
\hline Hydrochlorothiazide & 5.4 & 17.8 & 80 & 9 & -59 \\
\hline Ibuprofen & 11.7 & 38.6 & 32 & 17 & -43 \\
\hline Imipramine & 1.5 & 5.1 & 27 & 17 & -45 \\
\hline Indapamide & 5.0 & 16.7 & 72 & 17 & -50 \\
\hline Ketamine & 2.7 & 9.1 & 97 & 9 & -22 \\
\hline Ketoprofen & 4.1 & 13.5 & 78 & 16 & -56 \\
\hline Lamotrigine & 4.6 & 15.2 & 72 & 9 & -39 \\
\hline Levetiracetam & 7.0 & 23.1 & 96 & 7 & -43 \\
\hline Lidocaine & 2.3 & 7.6 & 97 & 5 & -2 \\
\hline Lincomycin & 3.4 & 11.4 & 91 & 15 & -13 \\
\hline Lorazepam & 3.4 & 11.2 & 63 & 8 & -31 \\
\hline Marbofloxacin & 6.7 & 22.1 & 64 & 8 & 28 \\
\hline Mefenamic acid & 7.4 & 24.6 & 28 & 9 & -56 \\
\hline Meloxicam & 5.4 & 17.9 & 48 & 9 & -41 \\
\hline Metformin & 10.2 & 34.0 & 88 & 12 & -85 \\
\hline Methylprednisolone & 3.5 & 11.6 & 86 & 15 & -53 \\
\hline Metronidazole & 3.2 & 10.8 & 95 & 13 & -37 \\
\hline Metoprolol & 5.1 & 16.8 & 93 & 9 & -30 \\
\hline Midazolam & 2.9 & 9.7 & 62 & 13 & -29 \\
\hline Mirtazapine & 0.9 & 3.1 & 77 & 12 & -16 \\
\hline Naproxen & 4.0 & 12.2 & 45 & 18 & -36 \\
\hline Niflumic acid & 4.7 & 15.5 & 42 & 14 & -11 \\
\hline Nitrazepam & 0.9 & 3.0 & 55 & 17 & -15 \\
\hline Norclozapine & 3.0 & 9.9 & 30 & 15 & 31 \\
\hline Nordiazepam & 4.0 & 12.2 & 42 & 12 & -19 \\
\hline Norephedrine & 1.4 & 4.7 & 96 & 11 & -23 \\
\hline Norfentanyl & 1.5 & 4.9 & 94 & 7 & -14 \\
\hline Norfloxacin & 5.1 & 16.8 & 87 & 13 & 17 \\
\hline Norketamine & 0.9 & 3.0 & 96 & 14 & -24 \\
\hline Norsertraline & 5.1 & 16.8 & 47 & 11 & -75 \\
\hline Nortriptyline & 2.3 & 7.7 & 30 & 20 & -14 \\
\hline Ofloxacin & 0.9 & 3.1 & 90 & 9 & -8 \\
\hline Olanzapine & 0.7 & 2.3 & 47 & 9 & -13 \\
\hline Omeprazole & 7.9 & 26.1 & 93 & 12 & -45 \\
\hline Oxazepam & 3.2 & 10.6 & 65 & 16 & -15 \\
\hline Oxolinic acid & 5.8 & 19.1 & 76 & 3 & -27 \\
\hline Oxytetracycline & 2.2 & 7.3 & 91 & 9 & -44 \\
\hline Paracetamol & 10.0 & 30.3 & 97 & 15 & -49 \\
\hline Paroxetine & 3.1 & 10.4 & 22 & 16 & -50 \\
\hline Pentobarbital & 1.1 & 3.80 & 119 & 15 & -87 \\
\hline Phenobarbital & 1.8 & 6.11 & 87 & 15 & -31 \\
\hline Phenytoin & 5.8 & 19.1 & 76 & 20 & -24 \\
\hline Primidone & 4.4 & 14.5 & 95 & 17 & -59 \\
\hline Progesterone & 3.3 & 11.1 & 71 & 20 & -51 \\
\hline Propranolol & 3.1 & 10.4 & 53 & 12 & -26 \\
\hline Ranitidine & 1.2 & 4.0 & 42 & 16 & -61 \\
\hline Risperidone & 5.4 & 17.9 & 26 & 20 & -12 \\
\hline
\end{tabular}


Table 1 (continued)

\begin{tabular}{|c|c|c|c|c|c|}
\hline & $\begin{array}{l}\text { MLOD } \\
\text { (ng g } \\
\text { d.w.) }\end{array}$ & $\begin{array}{l}\text { MLOQ } \\
\text { (ng g } \\
\text { d.w.) }\end{array}$ & $\begin{array}{l}\text { REC (\%) } \\
\left(40 \mathrm{ng} \mathrm{g}^{-1},\right. \\
n=6)\end{array}$ & $\begin{array}{l}\text { RSD } \\
(\%) \\
(n=6)\end{array}$ & $\begin{array}{l}\mathrm{ME} \\
(\%)\end{array}$ \\
\hline Ronidazole & 5.7 & 19.0 & 104 & 10 & -62 \\
\hline Salicylic acid & 3.0 & 9.8 & 99 & 7 & -61 \\
\hline Sarafloxacin & 1.0 & 3.3 & 43 & 10 & -24 \\
\hline Sertraline & 2.7 & 8.9 & 36 & 14 & -55 \\
\hline Simvastatin & 2.3 & 7.5 & 20 & 20 & -56 \\
\hline Sulfachloropyridazine & 4.4 & 14.5 & 56 & 20 & -24 \\
\hline Sulfaclozine & 10.7 & 35.7 & 56 & 12 & -72 \\
\hline Sulfadiazine & 5.7 & 19.0 & 70 & 13 & -46 \\
\hline Sulfadimethoxine & 5.0 & 16.8 & 52 & 10 & -31 \\
\hline Sulfadimidine & 3.8 & 12.6 & 59 & 14 & -39 \\
\hline Sulfadoxine & 4.7 & 15.8 & 61 & 11 & -37 \\
\hline Sulfaguanidine & 16.4 & 54.6 & 56 & 16 & -19 \\
\hline Sulfamerazine & 2.8 & 9.3 & 70 & 16 & -50 \\
\hline Sulfamethizole & 3.0 & 9.8 & 57 & 16 & -59 \\
\hline Sulfamethoxazole & 4.0 & 12.2 & 63 & 9 & -56 \\
\hline Sulfamethoxypyridazine & 7.8 & 25.9 & 55 & 11 & -38 \\
\hline Sulfamonomethoxine & 4.0 & 13.3 & 57 & 13 & -43 \\
\hline Sulfamoxole & 5.0 & 16.7 & 60 & 16 & -60 \\
\hline Sulfapyridine & 4.0 & 12.2 & 52 & 15 & -37 \\
\hline Sulfathiazole & 3.6 & 11.9 & 66 & 17 & -51 \\
\hline Sulfisoxazole & 7.8 & 25.9 & 61 & 15 & -42 \\
\hline Temazepam & 1.5 & 4.9 & 61 & 12 & -16 \\
\hline Tetracycline & 10.1 & 33.6 & 78 & 16 & -58 \\
\hline Theophylline & 3.6 & 11.9 & 98 & 11 & -69 \\
\hline Thiamphenicol & 6.1 & 20.3 & 107 & 16 & -80 \\
\hline Thiopental & 1.4 & 4.6 & 40 & 20 & -87 \\
\hline Tiamulin & 3.3 & 11.1 & 51 & 9 & -34 \\
\hline Topiramate & 2.0 & 6.6 & 95 & 14 & -84 \\
\hline Tramadol & 2.8 & 9.2 & 88 & 8 & -20 \\
\hline Triamterene & 3.0 & 10.1 & 68 & 9 & -31 \\
\hline Trimethoprim & 1.0 & 3.3 & 83 & 9 & -18 \\
\hline Tylosin & 5.7 & 19.0 & 78 & 8 & -22 \\
\hline Valproic acid & 12.9 & 43.0 & 107 & 6 & 38 \\
\hline Valsartan & 7.2 & 23.8 & 72 & 14 & -19 \\
\hline Venlafaxine & 2.4 & 7.9 & 89 & 11 & -21 \\
\hline Zopiclone & 4.6 & 15.4 & 88 & 11 & -28 \\
\hline \multicolumn{6}{|l|}{ Illicit drugs ${ }^{\mathrm{a}}$} \\
\hline 6-monoacetylmorphine & 4.6 & 15.4 & 100 & 10 & -22 \\
\hline Amphetamine & 1.5 & 5.0 & 97 & 15 & -27 \\
\hline Benzoylecgonine & 2.3 & 7.6 & 95 & 7 & -27 \\
\hline Buprenorphine & 0.6 & 2.0 & 50 & 16 & -13 \\
\hline Cocaine & 4.5 & 15.1 & 92 & 12 & -12 \\
\hline Codeine & 3.3 & 10.9 & 99 & 17 & -43 \\
\hline EME & 6.5 & 21.5 & 95 & 8 & -75 \\
\hline EDDP & 2.9 & 9.6 & 68 & 13 & -19 \\
\hline Heroin & 0.6 & 1.9 & 91 & 9 & -21 \\
\hline LSD & 4.8 & 16.1 & 60 & 10 & -18 \\
\hline
\end{tabular}

Table 1 (continued)

\begin{tabular}{llllll}
\hline & $\begin{array}{l}\text { MLOD } \\
\left(\mathrm{ng} \mathrm{g}^{-1}\right. \\
\text { d.w. })\end{array}$ & $\begin{array}{l}\text { MLOQ } \\
\left(\mathrm{ng} \mathrm{g}^{-1}\right. \\
\text { d.w. })\end{array}$ & $\begin{array}{l}\text { REC (\%) } \\
\left(40 \mathrm{ng} \mathrm{g}^{-1}\right.\end{array}$ & $\begin{array}{l}\text { RSD } \\
(\%) \\
(n=6)\end{array}$ & $\begin{array}{l}\text { ME } \\
(\%)\end{array}$ \\
\hline LSD-OH & 6.1 & 20.1 & 81 & 14 & 49 \\
MDA & 3.5 & 11.6 & 97 & 15 & -34 \\
MDEA & 4.3 & 14.3 & 94 & 13 & -37 \\
MDMA & 2.5 & 8.4 & 90 & 6 & 24 \\
Methadone & 4.7 & 15.8 & 46 & 14 & -27 \\
Methamphetamine & 0.9 & 2.9 & 87 & 8 & 27 \\
Morphine & 2.5 & 8.2 & 101 & 13 & -31 \\
Oxycodone & 3.9 & 12.9 & 101 & 9 & -28 \\
THCA & 14.3 & 47.7 & 31 & 20 & -78 \\
& & & & &
\end{tabular}

MLOD: method limit of detection; MLOQ: method limit of quantification; REC: recovery; ME: matrix effect

${ }^{\text {a }}$ For the sake of convenience all the opioids and opiates have been grouped as illicit drugs

To ensure a correct quantification, method precision was determined as relative standard deviation (\%RSD) from the recovery experiments ( $n=6,40 \mathrm{ng} \mathrm{g}^{-1}$ d.w.), processed by the method described (method repeatability). The precision limit of $<20 \%$ RSD was met for all analytes, indicating the good precision of the method.

Matrix effect is an important variable in the performance of LC-MS/MS analysis in complex matrices, including sewage sludge [26]. This variable was evaluated and the results, expressed as percentage of suppression or enhancement, are summarized in Table 1. In most cases, signal suppression was in the range -92 to -3 . Only for 12 out of the 148 target compounds was signal enhancement observed, in the range $11-90 \%$.
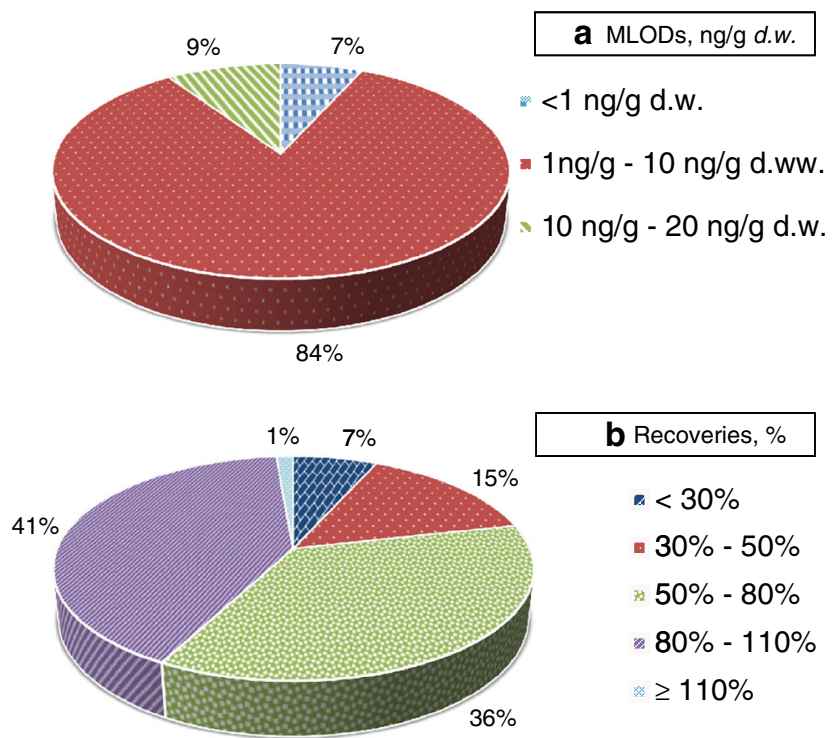

Fig. 2 Distribution of (a) MLODs (ng $\mathrm{g}^{-1}$ d.w.) and (b) recoveries $(\%, n=6)$ 
Application to real samples

The developed multi-residue method was used to evaluate the presence of the target compounds in different sewagesludge samples collected from five different WWTPs in Santorini (Greece), as described in "Sample collection and preparation". Table 2 shows the concentration values for every compound in each sample, and summarizes the frequencies of detection, the mean and median concentrations, and the ranges of concentration of the evaluated substances. Values $<$ LOQ were computed in the frequency because they were regarded as detected. In these cases, a value of $\mathrm{LOQ} / 2$ was assigned for calculating the mean and the median. Undetected compounds were not included in the table. Out of the 148 target compounds, 36 were determined at least in one sample, with mean and median concentrations up to $208 \mathrm{ng} \mathrm{g}^{-1}$ d.w. and $219 \mathrm{ng} \mathrm{g}^{-1}$ d.w., respectively.

Higher frequencies of detection (FD) and mean concentrations (MC) were obtained for compounds with relatively high values of $\log K_{\mathrm{OW}}$. Among these compounds were azithromycin (FD $100 \%$, MC $155.5 \mathrm{ng} \mathrm{g}^{-1}$ d.w.), amitriptyline (FD $100 \%$, MC $116.4 \mathrm{ng} \mathrm{g}^{-1}$ d.w.), diclofenac (FD $100 \%$, MC $40.9 \mathrm{ng} \mathrm{g}^{-1}$ d.w.), niflumic acid (FD $100 \%$, MC $43.5 \mathrm{ng} \mathrm{g}^{-1}$ d.w.), and sertraline (FD $100 \%$, MC $57.9 \mathrm{ng} \mathrm{g}^{-1}$ d.w.). Although the levels of some compounds in industrial wastewater (IWW) are not very high, these compounds are easily adsorbed onto the sludge and they can be determined at relevant levels. Furthermore, the results revealed high FD and MC for compounds that are not particularly lipophilic, but are present at high concentrations in the corresponding IWWs. As mentioned previously, sorption onto sludge does not only depend on the lipophilicity of the compounds, although it is an important factor. This was revealed by Yamamoto et al. [7], who found a weak relationship between the carbon-specific equilibrium sorption constant $\left(K_{\mathrm{OC}}\right)$ and the octanol-water distribution coefficient $\left(K_{\mathrm{OW}}\right)$ when studying a large number of pharmaceuticals. Other factors, including $\mathrm{pH}$, temperature, and ionic strength, also have an important effect and make it difficult to predict sorption processes. Among the compounds were acetylsalicylic acid (FD $100 \%$, MC $208.3 \mathrm{ng} \mathrm{g}^{-1}$ d.w.), metformin (FD $100 \%$, MC $64.5 \mathrm{ng} \mathrm{g}^{-1}$ d.w.), norfloxacin (FD $100 \%$, MC $52.9 \mathrm{ng} \mathrm{g}^{-1}$ d.w.), carbamazepine (FD $100 \%$, MC $41.8 \mathrm{ng} \mathrm{g}^{-1}$ d.w.), valproic acid (FD $100 \%$, MC $92.8 \mathrm{ng} \mathrm{g}^{-1}$ d.w.), tetracycline (FD $100 \%$, MC $100.0 \mathrm{ng} \mathrm{g}^{-1}$ d.w.), ciprofloxacin (FD $100 \%$, MC $78.5 \mathrm{ng} \mathrm{g}^{-1}$ d.w.), and citalopram (FD $100 \%$, MC $134.6 \mathrm{ng} \mathrm{g}^{-1}$ d.w.). All these compounds were determined at high concentrations in IWWs in other studies performed at the same sampling points [22] or at other places in Greece [23].

Also noteworthy is the high levels obtained for the metabolite 3,4-methylenedioxyamphetamine (MDA) (FD $60 \%$, MC $26.8 \mathrm{ng} \mathrm{g}^{-1}$ d.w.), indicating substantial consumption of 3,4-methylenedioxy- $N$-methylamphetamine (MDMA), a popular recreational drug. MDA was determined at higher levels in the sludge of the WWTPs of Kamari, Fira, and Ia, which are located in very touristy spots compared with the Karterados and Emporio WWTPs, which serve a more stable population and for which the concentration of this compound was significantly lower. However, THCA, a major metabolite of THC, was not detected in any sample. This compound is highly lipophilic and it is likely to be found in sludge [17], because consumption of THC is normally quite high. The reason for its nondetection could be the high MLOD obtained for THCA. Nevertheless, for most of the compounds no significant differences were observed among the levels for the different WWTPs evaluated, indicating a substantial use of the detected substances throughout the whole island. It is also important to remark that the monitoring study was performed with grab samples, and solid long-term conclusions cannot be extracted.

\section{Conclusions}

A multi-residue method based on USE and further analysis by LC-MS/MS was developed and optimized for the determination in sewage sludge of pharmaceuticals and illicit drugs with a wide range of psychochemical properties. This method is the first one enabling the determination of an extensive list of both pharmaceuticals and illicit drugs in sewage sludge. Good analytical performance was achieved, with MLODs below $10 \mathrm{ng} \mathrm{g}^{-1}$ d.w. for $91 \%$ of the analytes, enabling a reliable quantification of the target compounds in the complex selected matrix. The developed USE extraction method, and the fact that an extra clean-up step was not required, mean that the sample preparation is fast, efficient and non-tedious. A mixture of water and $\mathrm{MeOH}$ proved to be the optimum solvent to perform the USE extraction. The use of acidified water and EDTA significantly improved the extraction efficiency for several compounds. The optimization of the amount of sample and the extraction temperature also proved to be important. The addition of a small amount of FA into the vial before injection into the LC-MS/MS system led to a very significant improvement of the sensitivity for many compounds in $\operatorname{ESI}(+)$.

In the analysis of five different sewage-sludge samples from different WWTPs of Santorini 36 compounds were determined, some at concentrations above $100 \mathrm{ng} \mathrm{g}^{-1}$ d.w. The frequencies of detection and the mean concentrations were particularly high for the most lipophilic compounds 
Table 2 Concentrations of the detected compounds in sewage sludge from five WWTPs of Santorini Island. Mean, median, concentration range, and frequency of detection

\begin{tabular}{|c|c|c|c|c|c|c|c|}
\hline Kamari & Fira & Karterados & Emporio & Ia & $\begin{array}{l}\text { Mean } \\
\left(\text { ng g }^{-1} \text { d.w.) }\right.\end{array}$ & $\begin{array}{l}\text { Median } \\
\left(\text { ng g }^{-1} \text { d.w.) }\right.\end{array}$ & $\begin{array}{l}\text { Range } \\
\left(\text { ng g }^{-1} \text { d.w.) }\right.\end{array}$ \\
\hline
\end{tabular}

\begin{tabular}{|c|c|c|c|c|c|c|c|c|c|}
\hline \multicolumn{10}{|l|}{ Pharmaceuticals } \\
\hline 8-OH mirtazapine & n.d. & 7.1 & n.d. & $<\mathrm{LOQ}$ & $<\mathrm{LOQ}$ & 3.0 & 2.4 & $<$ LOQ-7.1 & 60 \\
\hline Acetylsalicylic acid & 209 & 226 & 143 & 219 & 244 & 208 & 219 & $143-244$ & 100 \\
\hline Alprazolam & $<\mathrm{LOQ}$ & $<$ LOQ & n.d & n.d & n.d & - & - & - & 40 \\
\hline Amitriptyline & 227 & 102 & 32.3 & 70.2 & 151 & 116 & 102 & $32.3-227$ & 100 \\
\hline Azithromycin & 149 & 267 & 228 & 72.8 & 60.8 & 156 & 149 & $60.8-267$ & 100 \\
\hline Caffeine & $<\mathrm{LOQ}$ & $<\mathrm{LOQ}$ & 13.4 & n.d. & 14.5 & 8.1 & 5.5 & $<$ LOQ-14.5 & 80 \\
\hline Carbamazepine & 30.8 & 29.1 & 18.0 & 113 & 18.4 & 41.8 & 29.1 & $18.0-113$ & 100 \\
\hline Cimetidine & n.d & n.d & 51.0 & $<\mathrm{LOQ}$ & 17.6 & 15.7 & 6.3 & $<\mathrm{LOQ}-51.0$ & 60 \\
\hline Ciprofloxacin & 34.1 & 100 & 72.4 & 55.7 & 115 & 78.5 & 72.4 & $34.1-115$ & 100 \\
\hline Citalopram & 168 & 113 & 110 & 130 & 153 & 135 & 130 & $110-168$ & 100 \\
\hline Clarithromycin & 16.3 & 41.4 & $<\mathrm{LOQ}$ & $<\mathrm{LOQ}$ & 21.1 & 18.0 & 16.3 & $<\mathrm{LOQ}-41.1$ & 100 \\
\hline Clomipramine & 24.6 & n.d. & 67.1 & $<\mathrm{LOQ}$ & $<\mathrm{LOQ}$ & 22.1 & 8.3 & $<\mathrm{LOQ}-67.1$ & 80 \\
\hline Clozapine & 21.0 & n.d. & 49.9 & n.d & n.d & 15.4 & 2.0 & $21.0-49.9$ & 40 \\
\hline Diclofenac & 39.1 & 42.1 & 40.9 & $<\mathrm{LOQ}$ & 65.3 & 40.9 & 40.9 & $<$ LOQ-65.3 & 100 \\
\hline Doxycycline & 64.0 & 154 & 179 & 81.3 & 77.1 & 111 & 81.3 & $64.0-179$ & 100 \\
\hline Ephedrine & 24.2 & 75.2 & 17.0 & $<\mathrm{LOQ}$ & 47.5 & 33.1 & 24.2 & $<\mathrm{LOQ}-75.2$ & 100 \\
\hline Fluoxetine & 35.3 & n.d. & $<\mathrm{LOQ}$ & 36.8 & n.d. & 17.3 & 8.8 & $<$ LOQ-36.8 & 60 \\
\hline Metformin & 75.2 & 65.6 & 62.0 & 41.4 & 78.2 & 64.5 & 65.6 & $41.4-78.2$ & 100 \\
\hline Metoprolol & 16.2 & $<\mathrm{LOQ}$ & n.d & n.d. & $<\mathrm{LOQ}$ & 6.3 & 5.8 & $<$ LOQ-16.2 & 60 \\
\hline Mirtazapine & 26.8 & 16.7 & 25.7 & 32.8 & 12.7 & 22.9 & 25.7 & $12.7-32.8$ & 100 \\
\hline Niflumic acid & 36.4 & 26.5 & 60.2 & 67.4 & 27.2 & 43.5 & 36.4 & $26.5-67.4$ & 100 \\
\hline Norfloxacin & 36.7 & 63.9 & 76.6 & 50.8 & 36.6 & 52.9 & 50.8 & $36.6-76.6$ & 100 \\
\hline Nortriptyline & 24.0 & 34.0 & 18.0 & $<\mathrm{LOQ}$ & 42.1 & 25.3 & 24.0 & $<\mathrm{LOQ}-42.1$ & 100 \\
\hline Ofloxacin & 23.0 & 35.9 & 21.0 & 15.0 & 42.0 & 27.4 & 23.0 & $15.0-42.0$ & 100 \\
\hline Oxytetracycline & 159 & 30.9 & 119 & 8.9 & 30.8 & 69.7 & 30.9 & $8.9-159$ & 100 \\
\hline Propranolol & 21.7 & n.d. & n.d. & n.d. & 24.1 & 10.1 & 1.6 & $21.7-24.1$ & 40 \\
\hline Ranitidine & 32.7 & 12.5 & 17.8 & 10.1 & n.d. & 14.7 & 12.5 & $10.1-32.7$ & 80 \\
\hline Salicylic acid & 17.3 & 33.1 & 14.2 & 13.8 & 12.1 & 18.1 & 14.2 & $12.1-33.1$ & 100 \\
\hline Sertraline & 42.8 & 65.1 & 52.9 & 20.1 & 108 & 57.9 & 52.9 & $20.1-108$ & 100 \\
\hline Sulfapyridine & 34.5 & 21.5 & 23.3 & 31.1 & 12.1 & 24.5 & 23.3 & $12.1-34.5$ & 100 \\
\hline Tetracycline & 125 & 191 & 71.6 & $<\mathrm{LOQ}$ & 102 & 100 & 102 & $<$ LOQ-191 & 100 \\
\hline Tramadol & 35.8 & 24.5 & 26.7 & 30.5 & 37.3 & 31.0 & 30.5 & $24.5-37.3$ & 100 \\
\hline Valproic acid & 89.3 & 55.8 & 129 & 93.7 & 96.0 & 92.8 & 93.7 & $55.8-129$ & 100 \\
\hline Venlafaxine & 29.6 & n.d. & 35.7 & $<\mathrm{LOQ}$ & n.d. & 14.3 & 4.0 & $<\mathrm{LOQ}-35.7$ & 60 \\
\hline \multicolumn{10}{|l|}{ Illicit drugs } \\
\hline Codeine $^{\mathrm{a}}$ & n.d & n.d & 21.0 & $<\mathrm{LOQ}$ & n.d. & 6.3 & 1.7 & $<\mathrm{LOQ}-21.0$ & 40 \\
\hline MDA & 24.7 & 77.3 & $<\mathrm{LOQ}$ & $<\mathrm{LOQ}$ & 20.5 & 26.8 & 20.5 & $<$ LOQ-77.3 & 100 \\
\hline
\end{tabular}

n.d., not detected; <LOQ, below limit of quantification

${ }^{a}$ Opiate compound but not illicit

(e.g. amitriptyline and sertraline) and also for those previously detected in these spots at high concentrations in IWW (e.g. acetylsalicylic acid and metformin). It should be pointed out that the treated sludge generated in the evaluated WWTPs is used in some cases as fertilizer in agriculture, and these practices may contribute to transferring these compounds to surface and groundwater. The target substances may be re-introduced into the water cycle and eventually into the food chain. Therefore, a greater knowledge regarding the presence and behavior of these compounds in sewage sludge is necessary to ensure safer management of the generated biosolids. 
Acknowledgments This project was implemented under the Operational Program «Education and Lifelong Learning» and funded by the European Union (European Social Fund) and National Resources - ARIS TEIA 624.

\section{References}

1. Zuccato E, Castiglioni S (2009) Illicit drugs in the environment. Phil Trans R Soc A 367:3965-3978

2. van Nuijs ALN, Mougel JF, Tarcomnicu I, Bervoets L, Blust R, Jorens PG, Neels H, Covaci A (2011) A one year investigation of the occurrence of illicit drugs in wastewater from Brussels, Belgium. J Environ Monit 13:1008-1016

3. Jones-Lepp TL, Alvarez DA, Petty JD, Huckins JN (2004) Polar organic chemical integrative sampling and liquid chromatography electrospray/ion-trap mass spectrometry for assessing selected prescription and illicit drugs in treated sewage effluents. Arch Environ Contam Toxicol 47:427-439

4. Pal R, Megharaj M, Kirkbride KP, Naidu R (2013) Illicit drugs and the environment - A review. Sci Total Environ 463-464:1079-1092

5. Zuccato E, Castiglioni S, Bagnati R, Chiabrando C, Grassi P, Fanelli R (2008) Illicit drugs, a novel group of environmental contaminants. Water Res 42:961-968

6. Daughton CG, Ruhoy IS (2009) Environmental footprint of pharmaceuticals: The significance of factors beyond direct excretion to sewers. Environ Toxicol Chem 28:2495-2521

7. Yamamoto H, Nakamura Y, Moriguchi S, Nakamura Y, Honda Y, Tamura I, Hirata Y, Hayashi A, Sekizawa J (2009) Persistence and partitioning of eight selected pharmaceuticals in the aquatic environment: Laboratory photolysis, biodegradation, and sorption experiments. Water Res 43:351-362

8. Fytili D, Zabaniotou A (2008) Utilization of sewage sludge in EU application of old and new methods: a review. Renew Sust Energ Rev $12: 116-140$

9. Verlicchi P, Al Aukidy M, Zambello E (2012) Utilization of sewage sludge in EU application of old and new methods: areview. Sci Total Environ 429:123-155

10. Li WC (2014) Occurrence, sources, and fate of pharmaceuticals in aquatic environment and soil. Environ Pollut 187:193-201

11. Baker DR, Kasprzyk-Hordern B (2011) Multi-residue determination of the sorption of illicit drugs and pharmaceuticals to wastewater suspended particulate matter using pressurised liquid extraction, solid phase extraction and liquid chromatography coupled with tandem mass spectrometry. J Chromatogr A 1218:7901-7913

12. Vazquez-Roig P, Blasco C, Picó Y (2013) Advances in the Analysis of Legal and Illegal Drugs in the Aquatic Environment. Trend Anal Chem 50:65-77

13. Wille K, De Brabander HF, De Wulf E, Van Caeter P, Janssen CR, Vanhaecke L (2012) Coupled chromatographic and mass- spectrometric techniques for the analysis of emerging pollutants in the aquatic environment. Trend Anal Chem 35:87-108

14. Zuloaga O, Navarro P, Bizkarguenaga E, Iparraguirre A, Vallejo A, Olivares M, Prieto A (2012) Overview of extraction, clean-up and detection techniques for the determination of organic pollutants in sewage sludge: a review. Anal Chim Acta 736:7-29

15. Jelic A, Petrovic M, Barceló D (2009) Multi-residue method for trace level determination of pharmaceuticals in soil samples using pressurized liquid extraction followed by liquid chromatography/ quadrupole-linear ion trap mass spectrometry. Talanta 80:363-371

16. Díaz-Cruz MS, García-Galan MJ, Guerra P, Jelic A, Postigo C, Eljarrat E, Farré M, López de Alda MJ, Petrovic M, Barceló D (2009) Analysis of selected emerging contaminants in sewage sludge. Trend Anal Chem 28:1263-1275

17. Mastroianni N, Postigo C, Lopez de Alda M, Barcelo D (2013) Illicit and abused drugs in sewage sludge:method optimization and occurrence. J Chromatogr A 1322:29-37

18. Senta I, Krizman I, Ahel M, Terzic S (2013) Integrated procedure for multiresidue analysis of dissolved and particulate drugs in municipal wastewater by liquid chromatography-tandem mass spectrometry. Anal Bioanal Chem 405:3255-3268

19. Langford KH, Reid M, Thomas KV (2011) Multi-residue screening of prioritized human pharmaceuticals, illicit drugs and bactericides in sediments and sludge. J Environ Monit 13:2284-2291

20. Jones-Lepp TL, Stevens R (2007) Pharmaceuticals and personal care products in biosolids/sewage sludge: The interface between analytical chemistry and regulation. Anal Bioanal Chem 387:1173-1183

21. Kaleta A, Ferdig M, Buchberger W (2006) Semiquantitative determination of residues of amphetamine in sewage sludge samples. J Sep Sci 29:1662-1666

22. Borova VL, Maragou NC, Gago-Ferrero P, Pistos C, Thomaidis NS (2014) Highly sensitive determination of 68 psychoactive pharmaceuticals, illicit drugs, and related human metabolites in wastewater by liquid chromatography-tandem mass spectrometry. Anal Bioanal Chem 406:4273-4285

23. Dasenaki ME, Thomaidis NS (2014) Multi-analyte method for the determination of pharmaceuticals inwastewater samples using solidphase extraction and liquid chromatography-tandem mass spectrometry Anal Bioanal Chem (Submitted)

24. Nieto A, Borrull F, Pocurull E, Marcé RM (2007) Pressurized liquid extraction of pharmaceuticals from sewage-sludge. J Sep Sci 30:979 984

25. Lillenberg M, Yurchenko S, Kipper K, Herodes K, Pihl V, Sepp K, Lohmus R, Nei L (2009) Simultaneousdetermination of fluoroquinolones, sulfonamides and tetracyclines in sewage sludge by pressurized liquid extraction and liquid chromatography electrospray ionization-mass spectrometry. J Chromatogr A 1216: 5949-5954

26. Gago-Ferrero P, Diaz-Cruz MS, Barcelo D (2011) Occurrence of multiclass UV filters in treated sewage sludge from wastewater treatment plants. Chemosphere 84:1158-1165 